\title{
MORPHOMETRIC ANALYSIS OF LUMBAR PEDICLE AND ITS ROLE
} IN DEGENERATIVE CHANGES

\author{
Nithya Marimuthu, Suresh Narayanan *, K.V.P. Suriyakumari.
}

Department of Anatomy, Sri Manakula Vinayagar Medical College and Hospital, Puducherry, India.

\section{ABSTRACT}

\begin{abstract}
Introduction: The anatomy of lumbar vertebrae is vital in understanding pathogenesis of chronic back pain and instrumentation during spinal procedures. The purpose of the study is to quantify the linear and angular parameters of the lumbar pedicles and its association with osteophyte formation.

Methods: Forty-six ossified dry lumbar vertebrae of Indian origin, age ranging from 55-75 years of unknown sex were studied. Their pedicle length $(\mathrm{PL})$, width $(\mathrm{PW})$ and height $(\mathrm{PH})$ were measured using digital Vernier caliper. The superior and lateral view digital photographs of the vertebrae were taken and its transverse pedicle angle (TPA) and sagittal pedicle angle (SPA) were measured using image J software.
\end{abstract}

Results: The vertebrae were given scores from 0 to 4 depending upon the osteophyte formation in body and lamina. The mean and standard deviation of the pedicle parameters were comparable with previously available studies. Results: On correlating the parameters with the osteophyte scoring, the SPA ( $p$ value $=0.017, r=0.350$ ) and $\mathrm{PH}$ ( $\mathrm{p}$ value $=0.015, r=0.357$ ) showed a positive correlation.

Conclusion: The data obtained from the study indicates the role of morphometry and angulation of the pedicle in degenerative changes of spine. These parameters can be used in radiology as a marker to detect early degenerative changes.

KEY WORDS: Pedicle, Morphometry, Lumbar, Degenerative scoring.

Address for Correspondence: Dr.N. Suresh, Assistant Professor, Department of Anatomy, Sri Manakula Vinayagar Medical College, Puducherry-605107, India. Phone: 0413-2643000, 2643014, Fax: 0413-2641549, E-Mail: nsuresh3888@gmail.com

Access this Article online Quick Response code

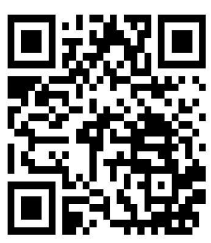

DOI: $10.16965 /$ ijar.2018.224

Journal Information

International Journal of Anatomy and Research

ICV for 2016
90.30
ISSN (E) 2321-4287 | ISSN (P) 2321-8967 https://www.ijmhr.org/ijar.htm DOI-Prefix: https://dx.doi.org/10.16965/ijar

\section{Article Information}

Received: 13 Apr 2018

Peer Review: 13 Apr 2018

Revised: None
Accepted: 30 May 2018

Published (O): 05 Jul2018

Published (P): 05 Jul 2018

\section{INTRODUCTION}

The vertebral column supports the trunk to maintain an upright posture by giving attachments to the muscles and protects the spinal cord and nerves [1]. In recent years, transpedicular screw fixation of spine has become the primary modality of treatment for fractured lumbar spine, gross spondylolisthesis and lumbar instabilities [2]. However, the success of technique depends on the size and path of the screw and on the presence or absence of osteoporotic changes over the pedicle [3].
Degeneration changes in spine occurs as a result of normal aging processes but can also be accelerated by poor posture and trauma [4]. Damage to the intervertebral disc causes excessive movements in the joints of the spine followed by formation of bone spurs on the surfaces of these joints [5]. These bone spurs also called osteophytes, predominantly observed in body and lamina can compress nerves in the lower back and can cause a variety of neurological symptoms ranging from radiating pain, weakness, stiffness of joints to numbness in the 
legs and feet [6]. The osteophytes on the vertebral bodies and lamina can also cause restriction of movements [7]. This new bone formation alters the load transmission and thereby alters the normal lumbar curvature resulting in scoliosis [4].

The objective of the study is 1) To measure the linear and angular parameters of the pedicles at various levels of lumbar vertebrae 2) To estimate the association between the pedicle parameters and the osteophyte score. Our hypothesis is that the load transmission across the lumbar vertebrae which plays a role in osteophyte formation might also alter the anatomy of the pedicles. The data obtained regarding the linear and angular parameters of the pedicle can help the surgeons to guide for a safer screw fixation in circumventing damage to the nerve roots, meninges and nearby vascular structures during spinal fusion surgeries [8].

\section{MATERIALS AND METHODS}

This was a cross sectional analytical study. A total of 46 fully ossified lumbar vertebrae, age ranging from $55-75$ years of unknown sex, available in the Department of Anatomy, Sri Manakula Vinayagar medical college, Puducherry was included in the study. The vertebrae having any deformities were excluded. The pedicle length $(P L)$ was measured from the junction of the transverse process and superior articular process to the point where the pedicle meets the vertebral body [8].

The pedicle width (PW) was measured between the medial and lateral surfaces of the pedicle at its midpoint, right angle to the pedicle axis. The pedicle height (PH) was measured as the vertical distance between superior and inferior border of the pedicle at its midpoint [8]. All measurements were taken from the external borders of the vertebral body rims, excluding any osteophytes. The linear parameters namely the PL, PW and PH were measured on both sides using digital Vernier caliper of $0.01 \mathrm{~mm}$ accuracy.

Superior and lateral view photographs were taken using a digital camera from a fixed distance avoiding parallax error. The transverse pedicle angle (TPA) was measured as the angle formed between the axis of the pedicle and a line passing through the vertebra axis in transverse plane. The pedicle axis was drawn by connecting the 2 points, the first point at the midpoint of the anterior part of pedicle in connection with the vertebral body; the second point at the midpoint of posterior part of the pedicle in connection with the transverse process. The vertebral axis was defined as a line joining the anterior most point of vertebral body and the bisecting point of the lamina (Figure 1). The Sagittal pedicle angles (SPA) were measured between the axis of the pedicle and the superior border of vertebral body in the sagittal plane [9]. The angular parameters were measured using image J software. After entering the data in Microsoft excel sheet, the mean between the sides were calculated for each parameter.

The vertebrae were given scores from 0 to 4 depending upon the osteophyte formation in body and lamina in eight different regions. The osteophyte scoring for vertebral body was done using the following criteria. Stage 0 shows no indication of osteophytosis with smooth rim (i.e., no lipping on the margin); stage 1 has one or two small osteophyte points $(<2 \mathrm{~mm}$ in length and width); stage 2 exhibits more developed osteophytosis, three or more small osteophyte points or larger osteophytes; stage 3 exhibits arthritic lipping or fused osteophytes that extend out either superiorly or inferiorly at least $3 \mathrm{~mm}$ in height; stage 4 has either partial or complete fusion of arthritic lipping or fused osteophytes between adjacent vertebrae [7] (Figure 2 and 3 ).

The osteophyte scoring for lamina was done using the following criteria. Stage 0 shows no indication of osteophytosis with smooth rim; stage 1 has one or two small osteophyte points ( $<2 \mathrm{~mm}$ in length and width); stage 2 exhibits more developed osteophytosis, three or more small osteophyte points or larger osteophytes; stage 3 exhibits three or more larger osteophytes and /or fused osteophytes (multiple points coming off 1 or more osteophytes) that cover $<50 \%$ of the area created by the articular facet and the midline; stage 4 has three or more larger osteophytes and D or fused osteophytes that cover $50 \%$ or more of the area created by the articular facet and the midline [7].

The data was entered in Microsoft excel sheet 
and analyzed using SPSS version 17.0 software. The mean and standard deviation were calculated. The strength of association between the parameters of pedicle and degenerative scores were calculated using Pearson's correlation coefficient and $p$ value of $<0.05$ was considered significant.

Fig. 1: Method of determining Transverse pedicle angle (TPA). TSA was measured between lines $A B$ and $B C$, by extending it posteriorly. $A B-$ Axis of the vertebral body; $\mathrm{BC}$ - Pedicle axis.

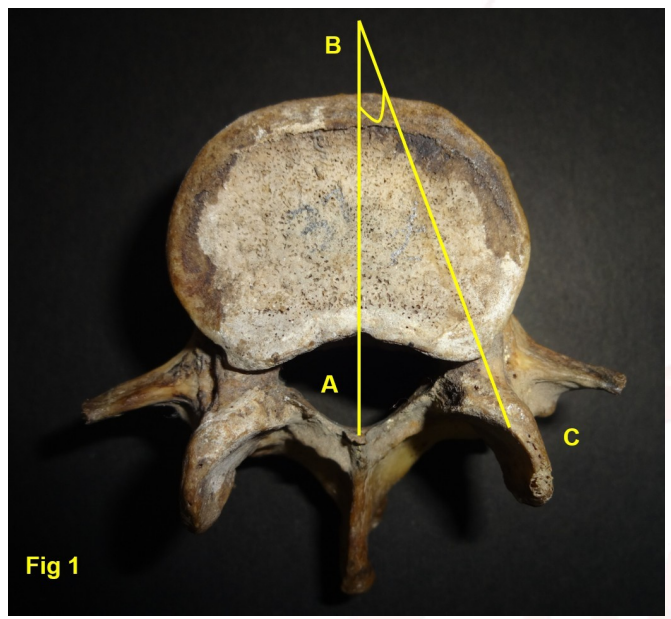

Fig. 2: Grade 1 osteophyte score over the vertebral body.

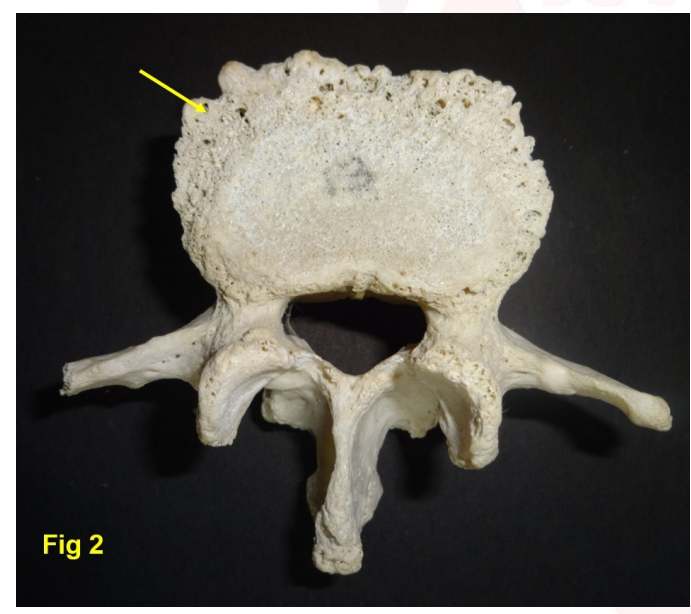

Fig. 3: Grade 3 osteophyte score over the vertebral body.

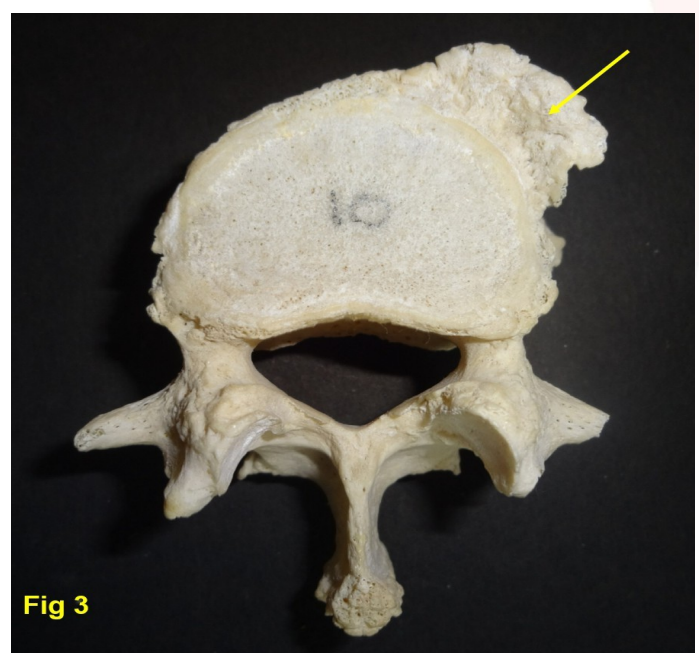

\section{RESULTS}

The results were, $P L$ of $L 1 \& L 2=6.57 \pm 0.72$, $L 3$ $=5.81 \pm 1.31, L 4=5.24 \pm 1.02, L 5=5.76 \pm 1.03$ $\mathrm{mm} ; \mathrm{PW}$ of $\mathrm{L} 1 \& \mathrm{~L} 2=6.49 \pm 2.11, \mathrm{~L} 3=7.13 \pm 1.6$, $\mathrm{L} 4=9.49 \pm 1.78, \mathrm{~L} 5=12.89 \pm 2.2 \mathrm{~mm}$; $\mathrm{PH}$ of $\mathrm{L} 1 \& \mathrm{~L} 2=14.3 \pm 1.18, \mathrm{~L} 3=13.77 \pm 0.84$, $\mathrm{L} 4=13.67 \pm 1.31, \mathrm{~L} 5=13.72 \pm 1.39 \mathrm{~mm}$. The mean TPA was $L 1 \& L 2=10.06 \pm 1.60, L 3=16.26$ $\pm 1.45, \mathrm{~L} 4=19.69 \pm 1.56, \mathrm{~L} 5=22.93 \pm 2.55$ degrees. The mean SPA was $L 1 \& L 2=5.61 \pm 0.73$, $\mathrm{L} 3=5.59 \pm 0.80, \mathrm{~L} 4=4.52 \pm 0.77, \mathrm{~L} 5=4.17 \pm$ 1.32 degrees. The sagittal pedicle angle ( $p$ value $=0.017, r=0.350$ ) and pedicle height ( $p$ value $=$ $0.015, r=0.357$ ) showed a positive correlation with degenerative score.

Table 1: Linear and angular parameters of present study.

\begin{tabular}{|c|c|c|c|c|c|}
\hline Vertebrae & $\begin{array}{c}\text { Pedicle } \\
\text { length } \\
(\mathrm{mm})\end{array}$ & $\begin{array}{c}\text { Pedicle } \\
\text { width }(\mathrm{mm})\end{array}$ & $\begin{array}{c}\text { Pedicle } \\
\text { height }(\mathrm{mm})\end{array}$ & $\begin{array}{c}\text { Transverse } \\
\text { pedicle angle } \\
\text { (in degrees) }\end{array}$ & $\begin{array}{c}\text { Sagittal } \\
\text { pedicle angle } \\
\text { (in degrees) }\end{array}$ \\
\hline $\mathrm{L} 1$ \& L2 (n=15) & $6.57 \pm 0.72$ & $6.49 \pm 2.11$ & $14.3 \pm 1.18$ & $10.06 \pm 1.60$ & $5.61 \pm 0.73$ \\
\hline $\mathrm{L} 3(\mathrm{n}=10)$ & $5.81 \pm 1.31$ & $7.13 \pm 1.6$ & $13.77 \pm 0.84$ & $16.26 \pm 1.45$ & $5.59 \pm 0.80$ \\
\hline $\mathrm{L} 4(\mathrm{n}=10)$ & $5.24 \pm 1.02$ & $9.49 \pm 1.78$ & $13.67 \pm 1.31$ & $19.69 \pm 1.56$ & $4.52 \pm 0.77$ \\
\hline $\mathrm{L} 5(\mathrm{n}=11)$ & $5.76 \pm 1.03$ & $12.89 \pm 2.2$ & $13.72 \pm 1.39$ & $22.93 \pm 2.55$ & $4.17 \pm 1.32$ \\
\hline
\end{tabular}

Table 2: Correlation between pedicle parameters and osteophyte scoring.

\begin{tabular}{|c|c|c|c|c|c|c|}
\hline & $\begin{array}{c}\text { PL ( } r \text { value } \\
\text { and } P \\
\text { value) }\end{array}$ & PW & PH & TPA & SPA & OS \\
\hline PL & 1 & & & & & \\
\hline PW & $\begin{array}{c}-0.361 \\
0.014^{* *}\end{array}$ & 1 & & & & \\
\hline PH & $\begin{array}{l}0.091 \\
0.549\end{array}$ & $\begin{array}{l}-0.101 \\
0.506\end{array}$ & 1 & & & \\
\hline TPA & $\begin{array}{c}-0.442 \\
0.002^{* *}\end{array}$ & $\begin{array}{c}0.735 \\
0.000^{* *}\end{array}$ & $\begin{array}{l}-0.13 \\
0.39 \\
\end{array}$ & 1 & & \\
\hline SPA & $\begin{array}{c}0.23 \\
0.125\end{array}$ & $\begin{array}{c}-0.415 \\
0.004^{* *}\end{array}$ & $\begin{array}{l}0.217 \\
0.148\end{array}$ & $\begin{array}{c}-0.345 \\
0.019^{* *}\end{array}$ & 1 & \\
\hline OS & $\begin{array}{l}0.096 \\
0.527\end{array}$ & $\begin{array}{l}-0.123 \\
0.417\end{array}$ & $\begin{array}{c}0.357 \\
0.015^{* *}\end{array}$ & $\begin{array}{l}-0.075 \\
0.622\end{array}$ & $\begin{array}{c}0.35 \\
0.017^{* *}\end{array}$ & 1 \\
\hline
\end{tabular}

$P$ value of $<0.05^{* *}$ indicates significant correlation

\section{DISCUSSION}

The pedicle is the strongest part of lumbar vertebrae and it acts as a strut to transmit forces between the body and neural arch. The load in thoracic and lumbar regions is transmitted through two vertical running columns, anteriorly by the vertebral bodies and intervertebral discs and posteriorly by the successive articulations of neural arch elements. The pedicle acts as a 
tie beam in connecting these two vertical columns thereby transferring the compressive force ${ }^{8}$. So, any damage to the pedicle anatomy can hinder the transmission of force resulting in deformities. Hence, the biomechanical role of pedicle is vital in understanding the pathogenesis of spondylosis, where there is an increase in $\mathrm{L} 5$ pedicle length and in lower back pain where there is an association of canal stenosis $[10,11]$.

The values of PL and PH in the present study, showed a gradual decrease from L1 to L4 with a mild increase in $\mathrm{L} 5$ level. The PW on the other hand showed a steady increase from L1 to L5. The results were similar to the dry bone-based studies by Lien et al and Reyes et al [8,12]. However, the PL and PW obtained from the present study is lower than a CT based study, where the average $P L$ and $P W$ of the lumbar vertebrae was 19.46 and $14.9 \mathrm{~mm}$ [2]. The difference in values could be due to the methodology involved. During pedicle screw insertion, the screw is introduced through the posterior aspect of the pedicle into the body of the vertebra anteriorly. Since the success of this technique depends upon the ability of the screw to obtain strength within the vertebral body, the choice of the screw to be used is determined by the minimum diameter of the pedicle. From the data gathered in the present study, the authors agree with previous recommendation of Steffee pedicle screws of $5.5 \mathrm{~mm}$ for lumbar instrumentation in Indian population [13].

The attachment and orientation of the pedicle varies in both transvers and sagittal plane. The TPA gradually increased as we moved caudal, with the maximum angulation at $L 5$ vertebrae. Similarly, there was a gradual decrease in the value of SPA from L1 to $L 5$. The results were similar to the dry bone and CT based studies done of western and Indian population [2].

The PL was influenced by both PW and TPA, negative correlation between PL and PW ( $p$ value $=0.014, r=-0.361)$ and negative correlation between PL and TPA ( $p$ value $=0.002, r=-0.442$ ) was observed. This indicates the elongation of pedicle along its axis reduces its width and narrows its orientation with the vertebral axis along the transverse plane. The PW was also influenced by both TPA and SPA, positive correlation between PW and TPA ( $p$ value $=<0.001, r=$ $0.735)$ and negative correlation between $\mathrm{PW}$ and SPA ( $p$ value $=0.004, r=-0.415)$ was observed. Increased width of the pedicle, widens its orientation with the vertebral axis in transverse plane and pushes it inferiorly in alignment with the vertebral body in sagittal plane. The TPA and SPA showed negative correlation ( $p$ value $=$ $0.019, r=-0.345)$ i.e. as the pedicle deviates away from the vertebral axis in transverse plane, the pedicle axis in sagittal plane becomes narrower.

Osteophytes are bony outgrowths formed due to excessive load transmission along the vertebral column, collapse of inter vertebral disc and weak vertebral column due to ageing [14]. These lumbar osteophytes were the focus of researchers to estimate age, sex differences and racial identification $^{5}$. The clinical focus is that, these osteophytes were also associated with abdominal aortic calcification, inferior vena cava obstruction and L5 root compression [6]. The average osteophyte score obtained in the present study was more in upper lumbar region, $(\mathrm{L} 1 \& \mathrm{~L} 2=8.73 \pm 5.69, \mathrm{~L} 3=7.4 \pm 6.26, \mathrm{~L} 4=6.3 \pm$ $3.92, \mathrm{~L} 5=5.55 \pm 5.59)$. As excessive mechanical loading was attributed to the formation of osteophytes, the authors anticipated higher score along the caudal vertebrae. Similar finding of higher incidence of osteophytes in the thoracic and upper lumbar region was reported in Korean skeletons [14]. From this study, it is clear that apart from increased loading in the lumbar region other factors like body movements, pedicle orientation and its height might play a role in bone spur formation.

In transpedicular screw fixation of spine, many studies have discussed the stability of the screws during different procedures but very few have focused the role of screw breakage, loosening and displacement and its etiology. Since a misplaced pedicle screw can damage the pedicle cortex, nerve root and facet joints, the biomechanical role of pedicle anatomy in maintaining the screw in its desired position is vital $[8,13]$. On comparing the parameters with the degenerative scoring, the SPA ( $p$ value $=0.017, r=$ 0.350 ) and $\mathrm{PH}$ ( $p$ value $=0.015, r=0.357$ ) showed a positive correlation with osteophyte score. In other words, excessive load transmission across 
the lumbar vertebrae was associated with increase in pedicle height and superior shift of the pedicle in sagittal plane above the vertebral axis. Thus, there is a possibility of the screw displacement which have to be taken into account during the post-operative care.

\section{CONCLUSION}

Previously done studies have focused on the morphometry of lumbar vertebrae using direct measurement, radiographs and CT scans or the prevalence of osteophytes independently. To our knowledge, this is the first study to investigate the role of lumbar pedicle morphometry and its association with degenerative changes. The authors observed positive correlation with $\mathrm{PH}$, SPA and osteophyte scoring. These results can be used as early markers in detecting degenerative changes and also in screening the people prone for developing lumbosacral pain later. The load transmission across the vertebrae should be included as a criterion in choosing the angulation and position of the screws during spinal instrumentation.

\section{ABBREVIATIONS}

PL - Pedicle length,

PW - Pedicle width,

PH - Pedicle height,

SPA - Sagittal pedicle angle,

TPA - Transverse pedicle angle

\section{Conflicts of Interests: None}

\section{REFERENCES}

[1]. Standring S, editor. Gray's Anatomy: The Anatomical basis of clinical practice. In: 40th ed. UK: Elsevier Health sciences; 2008. p. 712.

[2]. Abuzayed B, Tutunculer B, Kucukyuruk B, Tuzgen S. Anatomic basis of anterior and posterior instrumentation of the spine: morphometric study. Surg Radiol Anat. 2010 Jan 1;32(1):75-85.
[3]. Bhaumik M, Bapna N, Bhaumik U, Prabhakaran K. Study of transverse and sagittal diameters of lumbar pedicles in relation to trans-pedicular screw fixation using MRI in Rajasthan population. Int J Curr Res Rev. 2013;5(21):50-5.

[4]. Nishi K, Saiki K, Imamura T, Okamoto K, Wakebe T, Ogami K, et al. Degenerative changes of the sacroiliac auricular joint surface-validation of influential factors. Anat Sci Int. 2017 Sep 1;92(4):530-8.

[5]. Van der Merwe AE, I-can MY, L'Abbè EN. The pattern of vertebral osteophyte development in a South African population. Int J Osteoarchaeol. 2006 Sep 1;16(5):459-64.

[6]. Klaassen Z, Tubbs RS, Apaydin N, Hage R, Jordan R, Loukas M. Vertebral spinal osteophytes. Anat Sci Int. 2011 Mar 1;86(1):1-9.

[7]. Zukowski LA, Falsetti AB, Tillman MD. The influence of sex, age and BMI on the degeneration of the lumbar spine. J Anat. 2012 Jan;220(1):57-66.

[8]. Castro-Reyes CD, Morales-Avalos R, Vílchez-Cavazos F, Garza-Castro O de la, Salinas-Zertuche A, Aguirre POM, et al. Morphometric characteristics of lumbar vertebral pedicles in Mexican population. Implications for transpedicular lumbar fusion surgery. J Morphol Sci. 2015;32(1):37-42.

[9]. Nojiri K, Matsumoto M, Chiba K, Toyama Y. Morphometric analysis of the thoracic and lumbar spine in Japanese on the use of pedicle screws. Surg Radiol Anat. 2005 Apr 1;27(2):123-8.

[10]. Bajwa NS, Toy JO, Ahn NU. L5 Pedicle Length Is Increased in Subjects With Spondylolysis: An Anatomic Study of 1072 Cadavers. Clin Orthop. 2012 Nov;470(11):3202-6.

[11]. Kapoor Y, Sherke A., Krishnaiah.M, Suseelamma.D. Morphometry of the Lumbar vertebrae and its clinical significance. Sch J Appl Med Sci. 2014;2(3C):1045-52.

[12]. Lien S-B, Liou N-H, Wu S-S. Analysis of anatomic morphometry of the pedicles and the safe zone for through-pedicle procedures in the thoracic and lumbar spine. Eur Spine J. 2007 Aug 13;16(8):1215-22.

[13]. Chawla K, Sharma M, Abhaya A, Kochhar S. Morphometry of the lumbar pedicle in North West India. Eur J Anat. 2017 Oct 7;15(3):155-61.

[14]. Kim DK, Kim MJ, Kim Y-S, Oh CS, Shin DH. Vertebral osteophyte of pre-modern Korean skeletons from Joseon tombs. Anat Cell Biol. 2012 Dec;45(4):274-81.

How to cite this article:

Nithya Marimuthu, Suresh Narayanan, K.V.P. Suriyakumari. MORPHOMETRIC ANALYSIS OF LUMBAR PEDICLE AND ITS ROLE IN DEGENERATIVE CHANGES. Int J Anat Res 2018;6(3.1):54315435. DOI: 10.16965/ijar.2018.224 